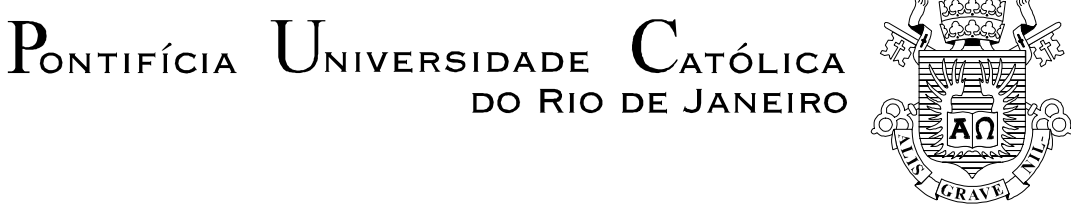

Joanna Vieira Noronha

De Desdêmona a Alice: Gênero, Ação Política e Violência Doméstica

\author{
Dissertação de Mestrado
}

Dissertação apresentada como requisito parcial para obtenção de grau de Mestre pelo Programa de PósGraduação em Direito do Departamento de Direito da PUC-Rio.

Orientadora: Bethânia Assy

Rio de Janeiro

Agosto de 2010 


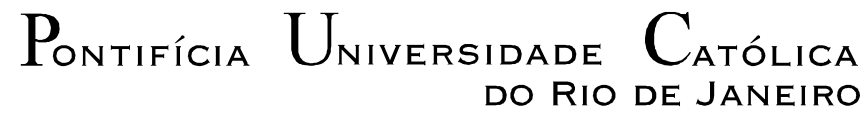

DO RIO DE JANEIRO

\author{
Joanna Vieira Noronha
}

\title{
De Desdêmona a Alice: Gênero, Ação Política e Violência Doméstica
}

Dissertação de Mestrado

Dissertacão apresentada ao Programa de Pósgraduaçẳo em Direito da PUC-Rio como requișito parcial para obtenção do grau de Mestre em Direito. Aprovada pela Comissâo Examinadora abaixo assinada.

Prof. Bethânia Assy

Orientadora

Departamento de Direito - PUC-Rio

Prof ${ }^{a}$. Márcia Nina Bernardes

Co-orientadora

Departamento de Direito - PUC-Rio

Prof. Sérgio Carrara

IMS- UERJ

Prof. José Maria Gomez

Departamento de Direito - PUC-Rio

Profa. Mônica Herz

Vice-Decana de Pós-Graduação do Centro de

Ciências Sociais - PUC-Rio

Rio de Janeiro, 16 de agosto de 2010 
Todos os direitos reservados. É proibida a reprodução total ou parcial do trabalho sem autorização da universidade, da autora e da orientadors.

\section{Joanna Vieira Noronha}

Graduou-se em Direito na UERJ (Universidade do Estado do Rio de Janeiro) em 2007. Bolsista pelo $\mathrm{CNPq}$ durante o curso de mestrado na PUC-Rio. Bolsista pelo CBIE (Canadian Bureau of International Education) para período de pesquisa na Universidade de Toronto. Membra do grupo de pesquisa em direito e gênero do departamento de direito da PUC-Rio.

Ficha Catalográfica

Noronha, Joanna Vieira

De Desdêmona a Alice: Gênero, Ação Política e Violência Doméstica / Joanna Vieira Noronha; orientadora: Bethânia de Albuquerque Assy - Rio de Janeiro: PUC, Departamento de Direito, 2010.

v., $110 \mathrm{f} .:$ il. ; $29,7 \mathrm{~cm}$

1. Dissertação (mestrado) - Pontifícia Universidade Católica do Rio de Janeiro, Departamento de Direito.

Inclui referências bibliográficas.

1. Direito - Teses. 2. Identidade. 3. Mulheres. 4. Judith Butler. 5. Feminismo. 6. Direitos Humanos. 7. Violência Doméstica. 8. Violência contra Mulhere. 9. Violência baseada em Gênero. 10. Brasil. 11. Maria da Penha. I. Assy, Bethânia de Albuquerque . II. Pontifícia Universidade Católica do Rio de Janeiro. Departamento de Direito. III. Título. 

de quaisquer gêneros. 


\section{Agradecimentos}

Às orientadoras Márcia Nina Bernardes e Bethânia Assy, pela paciência, por toda a ajuda e pela inspiração.

A todos os professores da PUC- Rio que participaram de alguma forma dessa jornada e ao Professor Sérgio Carrara, membro externo da Comissão Examinadora.

Ao $\mathrm{CNPq}$, à PUC-Rio e ao CBIE, pelos auxílios concedidos e sem os quais essa dissertação não poderia ser realizada.

Aos professores da Universidade de Toronto, em especial a Rebecca Cook, Joanna Erdman e Michael Trebilcock, por tudo o que aprendi com eles.

Aos colegas de mestrado, em especial a Carolina Santana, Marina Lacerda, Érico Bastos, Adriana Cruz e Julia Martins, por tudo o que vivemos juntos nesses dois anos. Tenho certeza que os laços que agora nos unem são muito mais que só intelectuais e que vão durar mesmo que agora tenhamos voltado à sala de aula mais ampla de todas.

Às colegas do grupo de pesquisa em gênero e direito, em especial a Adriana Vidal, por ter me apresentado Judith Butler e por todas as discussões acaloradas, e a Maria Negreiros e Maria Fernanda Marques, pela ajuda.

Aos funcionários da Secretaria do Departamento, em especial a Anderson Torres, por sua simpatia imbatível e suas prestatividade e competência fora de série.

Às melhores amigas que qualquer mestranda poderia ter: Cecília Dante, Tábata Lisbôa e Clara Machline.

A Mariana Prado, em especial por me apresentar a Universidade de Toronto e me ajudar a sobreviver ao inverno canadense. Todo o resto não cabe aqui - mas espero que saibas.

Aos meus pais e irmão, por tudo. 


\section{Resumo}

Noronha, Joanna Vieira; Assy, Bethânia de Albuquerque. De Desdêmona a Alice: Gênero, Ação Política e Violência Doméstica. Rio de Janeiro, 2010. 110p. Dissertação de Mestrado - Departamento de Direito, Pontifícia Universidade Católica do Rio de Janeiro.

Essa dissertação busca analisar o papel da ação política centrada em uma identidade - aqui, o conceito "mulher" - para o acesso à esfera pública hegemônica e para utilizar o direito como ferramenta de paridade participatória e empoderamento. Tomando por base esses três conceitos-chave (identidade, ação política e direito) e suas interações, buscar-se-á explorar possibilidades e limites da ação política centrada em um conceito fechado de agente para garantir direitos ao grupo que se pretende representar. A partir da apresentação de importantes exclusões dadas dentro dos movimentos feministas, utiliza-se um recorte da obra da filósofa feminista Judith Butler para construir a lente teórica que guiará a análise. O processo de formulação e promulgação da lei Maria da Penha de 2006, que lida com a violência doméstica e familiar contra mulheres, assim como as exclusões que se pode enxergar no texto dessa lei, formam o contexto escolhido para ilustrar a análise, por fornecer tanto exemplos das possibilidades e dos limites tratados em teoria, como também para que se pudesse obter um recorte adequado do tema.

\section{Palavras-Chave}

Identidade; Mulheres; Judith Butler; Feminismo; Direitos Humanos; Violência Domestica; Violência contra Mulheres; Violência Baseada em Gênero; Brasil; Maria da Penha. 


\section{Abstract}

Noronha, Joanna Vieira; Assy, Bethânia de Albuquerque Assy (Advisor). From Desdemona to Alice: Gender, Political Action and Domestic Violence. Rio de Janeiro, 2010. 110p. MSc. Dissertation - Departamento de Direito, Pontifícia Universidade Católica do Rio de Janeiro.

This dissertation aims at analyzing the role of political action based on identity here, the concept of "women" - to gain the hegemonic public sphere and use law as a tool for participation parity and empowerment. Using these three key concepts (identity, political action and law) and their interactions, this work hopes to show some possibilities and limits of a political action based on a closed concept of agent. Departing from the presentation of important exclusions occurred within feminist movements, a part of feminist philosopher Judith Butler is used to form a lens that will guide further analysis. The formulation and enactment process of the Maria da Penha statute, concerning domestic and familiar violence against women, alongside the exclusions one may notice in this statute, form the chosen context of analysis, for it provides examples of both possibilities and limits presented in theory. It also allowed for adequate framing of such a complex theme.

\section{Keywords}

Identity; Women; Judith Butler; Feminism; Human Rights; Domestic Violence; Violence against Women; Gender-Based Violence; Brazil; Maria da Penha. 


\section{Sumário}

1. Introdução 9

2. Gênero, Identidade, Ação Política e Exclusão 21

2.1 Contrapúblicos subalternos como formas

de combater a exclusão e acessar a esfera pública hegemônica $\quad 21$

2.2 Mascarando a exclusão: o publico privado e o privado público 30

2.3 Discursos que castram: biologia como destino e o binário de

sexo/gênero

3. Problematizando o Gênero

3.1 Em nome de quem fala - e em nome de quem pretendem falar - os movimentos feministas?

3.2 A crítica ao binário de sexo/gênero como conceitos estabilizadores e condições de inteligibilidade

3.3 O questionamento da necessidade de um conceito fechado de agente anterior

à ação política (doer behind the deed)

3.4 A viabilidade do conceito aberto

de agente de Butler como uma alternativa

4. Identidade: Possibilidades, Limites e Alternativas

4.1 Violência doméstica contra mulheres - Fatos

4.2. Violência doméstica e a ação política centrada

em gênero : a lei Maria da Penha

4.3 Marque uma das duas opções: os ponteiros

de sexo/gênero/desejo como um modelo para

visualizar a complexidade ininteligível

82

5. Conclusão

6. Referências Bibliográficas 